\title{
Analytical Determination of Boron in Irrigation Water Using Azomethine-H: Spectrophotometry
}

\author{
Mohammed, $\mathrm{Y} \mathrm{I}^{* 1,2}$, Garba, $\mathrm{K}^{2}$ and Umar, $\mathrm{S}^{3}$ \\ ${ }^{1}$ School of Chemical and Environmental Engineering, the University of Nottingham Malaysia Campus, Jalan Broga 43500 \\ Semenyih, Selangor, Darul Ehsan, Malaysia \\ ${ }^{2}$ Chemical Engineering Programme, Abubakar Tafawa Balewa University P.M.B 0248, Bauchi \\ ${ }^{3}$ Chemical Engineering Department, the Federal Polytechnic P.M.B 55, Bida, Nigeria
}

\begin{abstract}
Boron level in irrigation water is an important factor for high yield and quality agricultural production. Concentration below 1ppm provides plants with proper development and higher concentration poses toxicity problem. This necessitates for the use of accurate technique for assessment of boron in the irrigation water. Several analytical methods have been used for determination of boron in water and waste water systems but optimization of measurement condition has not been fully carried out. Analytical method was developed using azomethine-H. Effect of ascorbic acid and $p H$ were investigated. From the result obtained, it was found that ascorbic acid in the reagent serves as antioxidant and optimum $\mathrm{pH}$ for measurement was found to be $5.24 \pm 0.02$ at room temperature and wavelength of $415 \mathrm{~nm}$. This method showed wide linearity of up to 3ppm boron, good sensitivity and accuracy with limit of detection of 0.0514ppm within 95\% confidence level. It can be concluded that this technique is better effective than the existing methods for boron determination in aqueous solution.
\end{abstract}

Keywords: Boron, Spectrophotometry, Azomethine-H, Irrigation-water, Absorbance

\section{Introduction}

Boron is an essential element for plant growth at low concentration. Its functions include cell wall growth and improvement, cell division, fruit and seed development, sugar transportation and hormone development. Required concentration of boron in water represents an important factor for high yield and quality agricultural production [1].Boron concentration below 1ppm provides plants with proper development and higher concentration poses toxicity problem [2]. This therefore requires accurate technique for determination of boron level in water for agricultural production.

Analytical procedure provides means of assessing and monitoring of substance or substances in environment, water, soil and biological materials in both qualitative and quantitative terms. The qualitative findings establish the presence of a particular analyte in a sample while the quantitative is concern with amount of analyte in the specimen. Several methods are available for detecting boron in aqueous environments which can be classified as plasma based technique, mass spectrometry technique, ionometric approach and spectrophotometry method [3]. Each of these methods has advantages, disadvantages and limits of detection. Therefore, prior knowledge of concentration range of analyte in the sample to be investigated is needed in order to select appropriate analytic method.

Plasma based method also known as inductively coupled plasma (ICP) converts the boron species in the sample to elemental boron, further ionizes it to $\mathrm{B}^{+}$and then examined through detectors such as optical emission spectroscopy (OES), mass spectroscopy (MS). In the ICP-OES, wavelength of radiation released from the energized particles represents the properties of the element [4]. The ICP-MS determines boron by measuring the mass to charge ratio of the ion which gives both concentration and the stable isotope [3]. In general, this method has been utilized for samples from seawater, fresh water [5] plant, soil and biological specimen [6]. The main pluses of ICP method is that large amount of samples can be analyzed within a short period of time. The disadvantages include memory effect, mass fractionation and interference due to spectral overlapping [7-10].

Mass spectrometry technique involves the use of thermal ionization to generate ions. This can be operated in both positive and negative modes and is generally referred to as positive thermal ionization mass spectroscopy (PTIMS) and negative thermal ionization mass spectroscopy (NTIMS)[3]. PTIMS method consists of pretreatment stage that involves separation of boron in the sample and converts it to metaborate complex by addition of basic salt. The complex is then ionized to metaboratecation in form of $\mathrm{MBO}_{2}{ }^{+}$and sent to detector where mass to charge ratio is measured [11, 12]. In NTIMS, similar procedure is carried out but measurement is done in form of $\mathrm{BO}_{2}^{-}$. It requires no addition of basic salt, less pretreatment and has high sensitivity [7, 13]. Both PTIMS and NTIMS however have problems of mass fractionation and spectra interferences but more pronounced in PTIMS [7, 14].

Ionometric approach involves conversion of boron in sample to tetrafluoroborate ion by treating the sample with hydrogen fluoride HF. The tetrafluoroborate ion is then quantified potentiometrically through a suitable tetrafluoroborate ion selective electrode $[3,9]$. This method is susceptible to high degree of error when boron concentration in the sample is low due to decrease in sensitivity of the electrode. In addition, the tetrafluoroborate electrode has interference problem from anions such as nitrate, sulfate, and iodide which in turn affect its applicability [15].

Spectrophotometry is a non-mass spectrometry technique for boron determination in samples based on the use of specific reagents. It is subdivided in to two categories, the colorimetric and the fluorimetric. In colorimetric method, the reagents react with boron in solution to form colored boron complexes which is passed through a detector where the amount of light absorbed is measured at a wavelength equivalent to the color properties of the reagent used [3,16]. The commonly used reagents in this regard are curcumin, carmine and azomethine- $\mathrm{H}$ at 550, 605 and $410 \mathrm{~nm}$ wavelength respectively [16- 
18]. The fluorimetric method involves formation of fluorescent compounds from reaction between boron and the reagents and fluorescence of the compounds is then measured in the detection unit. Chromotropic acid and Alizarin Red are the frequently used fluorimetric reagents $[3,9]$. Azomethine- $\mathrm{H}$ is the most widely used spectrophotometric method owing to the fact that it is simple, fast, sensitive and has least interference with other chemical species [3,9].

The Azomethine-H approach can be used for both batch and continuous mode of analysis but optimization of measurement condition has not been fully carried out.

The objective of this study is to establish the optimum conditions for boron determinationin irrigation water using the azomethine-H spectrophotometry technique.

\subsection{Materials and Equipment}

\section{Methodology}

All the reagents used in this study were of analytical grade supplied by Fisher Scientific, United Kingdom.

Two azomethine- $\mathrm{H}$ reagents were prepared.The first sample was made by dissolving $0.5 \mathrm{~g}$ Azomethine- $\mathrm{H}$ and $1 \mathrm{~g}$ of ascorbic acid in $50 \mathrm{ml}$ of distilled water and transferred to a plastic bottle. The second sample was made of same amount of azomethine- $\mathrm{H}$ without ascorbic acid in $50 \mathrm{ml}$ of distilled water in similar bottle.

Buffer solution was made by dissolving $50 \mathrm{~g}$ of ammonium acetate in $100 \mathrm{ml}$ of distilled water followed by addition of $25 \mathrm{ml}$ of glacial acetic acid and $1.4 \mathrm{~g}$ of EDTA disodium salt.

UV-Vis CECIL CE 1021, 1000 series spectrophotometer was calibrated according to the manufacturer's manual and used to determine absorbance at a particular wavelength with $10 \mathrm{~mm} 100-\mathrm{Qs}$ cell.

Sample preparation

Various boron solutions were prepared from boron standard solution of $1000 \mathrm{ppm}$ to mimic the concentration of boron in irrigation water. Three different sub-samples; 100, 20 and 10ppmB were prepared from the stock by pipeting 10, 2 and $1 \mathrm{ml}$ respectively and diluting with distilled water to make up $100 \mathrm{ml}$ each. Several boron solutions between $0.1-10 \mathrm{ppm}$ were prepared from the sub-samples and UV-Vis was used to record absorbance for establishment of boron calibration graph.

\subsection{Sample treatment}

Samples prepared for analysis were treated as follows: Known amount of buffer solution was added to $10 \mathrm{ml}$ of the sample. Then, followed by some drops of azomethine- $\mathrm{H}$ reagent in a plastic bottle and stored in a dark space for a certain period of time. Thereafter, the absorbance readings were taken from the UV-Vis spectrophotometer. Procedures 2.2 and 2.3 were carried out in triplicates.

\subsection{Analytical Method Development}

The azomethine reagent was made from azomethine- $\mathrm{H}$ and ascorbic. $0.5 \mathrm{~g}$ of azomethine- $\mathrm{H}$ and $1 \mathrm{~g}$ of ascorbic acid dissolved in $50 \mathrm{ml}$ distilled water which translates to 0.0216 and $0.1136 \mathrm{M}$ respectively. In order to investigate the effect of ascorbic acid in the reagent, two fresh solutions of $0.0216 \mathrm{M}$ azomethine- $\mathrm{H}$ were made, one with ascorbic and other without ascorbic acid at $\mathrm{pH} 5.24$ and stored in a dark place at room temperature. After every 30 mins, the colour development in the reagents varied greatly. It was observed that ascorbic free reagent darkened at a faster rate while no change in colour was observed in the reagent with ascorbic acid. The same procedure was again followed and the $\mathrm{pH}$ adjusted to 2.0, 3.0, 6.0 and 8.0. Similar observations were noted. This indicates that the presence of ascorbic acid in the reagent prevented it from oxidation. The integrity therefore could be maintained throughout certain experimental period. The extent of this stability was further scrutinized. Another azomethine sample was prepared containing the same amount of ascorbic acid and stored in a plastic bottle. After every 15 mins, no noticeable change in colour was observed. This continued for about 20 hours and thereafter changes were noted. This indicates that azomethine reagent containing ascorbic acid can be used for a period up to 20 hours from the time of its preparation.

To further investigate the effect of ascorbic acid on the azomethine- $\mathrm{H}$, absorption spectra of azomethine-H were examined. Two fresh samples were prepared, one with ascorbic and the other without ascorbic acid. $2.5 \mathrm{ml}$ of each sample were added separately to $10 \mathrm{ml}$ of distilled water which is equivalent to $4.32 \times 10^{-3} \mathrm{M}$ of azomethine- $\mathrm{H}$ and the scans were conducted at various $\mathrm{pH}$ and wavelength using distilled water as blank.

\section{Discussion of Result}

Plots of absorbance against wavelength were obtained for the two scenarios as shown in Figure 1 and 2 below. Similar trends were obtained from the plots which confirm that the presence of ascorbic acid in the reagent has no effect on the absorption spectra of azomethine-H. The plots also show shift in spectra with respect to $\mathrm{pH}$. This may be due to the nature of ionized azomethine- $\mathrm{H}$ species present in the sample. This situation is more obvious at $\mathrm{pH}$ value of 7 and above. However, in the acidic medium that is, $\mathrm{pH}$ values between 2 to 6 , the changes tend to diminish from 400 to $430 \mathrm{~nm}$ wavelength. This therefore provides an idea of $\mathrm{pH}$ less sensitive region for the measurement. Since the principle of Azomethine- $\mathrm{H}$ method is based on formation of color complex with boron in the sample, another scan was conducted at different $\mathrm{pH}$ with fresh $10 \mathrm{ml}$ of sample containing $0.5 \mathrm{ppm}$ boron and $2.5 \mathrm{ml}$ of reagent $(2.5 \mathrm{ml}$ of azomethine- $\mathrm{H}$ with ascorbic acid) was added. The reagent was used as blank. The plot obtained shows that azomethine-boron complex is also affected by the $\mathrm{pH}$ of the solution as shown in Figure 3 below. The absorbance of the complex tends to stabilize in the acidic region between wavelengths of 410 to $430 \mathrm{~nm}$, although there were differences in the spectra. Full stability in absorbance value was observed at $\mathrm{pH}$ of 5.28 starting from $410 \mathrm{~nm}$ wave length. This reveals that measurement can be carried out between 
wavelength of 410 and $430 \mathrm{~nm}$ with proper control $\mathrm{pH}$ of the solution within 5.2-5.3. Wave length of $415 \mathrm{~nm}$ was adopted for this experiment.

The above investigation has identified the need for proper control of solution $\mathrm{pH}$ in order to take measurement at $415 \mathrm{~nm}$. Adequate buffer solution is required to maintain the $\mathrm{pH}$ within the appropriate range. A buffer solution was then prepared by dissolving $50 \mathrm{~g}$ of ammonium acetate in $100 \mathrm{ml}$ distilled water followed by addition of $25 \mathrm{ml}$ of glacial acetic acid. $1.4 \mathrm{~g}$ of EDTA salt was added to avoid any interference from other ions during boron measurement stage. The solution was subjected to several tests. Two sets of distilled water with $\mathrm{pH}$ adjusted to 3.5 and 9.5 were treated as follows: $1 \mathrm{ml}$ of buffer solution was added to $10 \mathrm{ml}$ of each water sample followed by $4 \mathrm{ml}$ of azomethine reagent to make up total volume of $15 \mathrm{ml}$. The $\mathrm{pH}$ values of resulting mixtures were found to be 5.33 and 5.37 respectively. The same procedure was repeated for 1.5, 2.0 and $2.5 \mathrm{ml}$ of buffer with corresponding azomethine volume of $3.5,3$ and 2.5 and the $\mathrm{pH}$ of final mixtures were 5.30, 5.26 and 5.24 for water sample at initial $\mathrm{H}$ value of 3.5 and 5.33, 5.30 and 5.26 for sample at $\mathrm{pH}$ 9.5. Boron solutions of $0.5 \mathrm{ppm}$ at different $\mathrm{pH}$ were treated in a similar manner with $2.5 \mathrm{ml}$ of buffer and $2.5 \mathrm{ml}$ azomethine. The $\mathrm{pH}$ of final solution is shown in Figure 4 below. The figure clearly indicated the effectiveness of the buffer solution in controlling the $\mathrm{pH}$ within the desired range. Thus, it is recommended that for every $10 \mathrm{ml}$ of sample, $2.5 \mathrm{ml}$ buffer and $2.5 \mathrm{ml}$ of azomethine reagent should be used. This procedure was adopted throughout the following investigations.

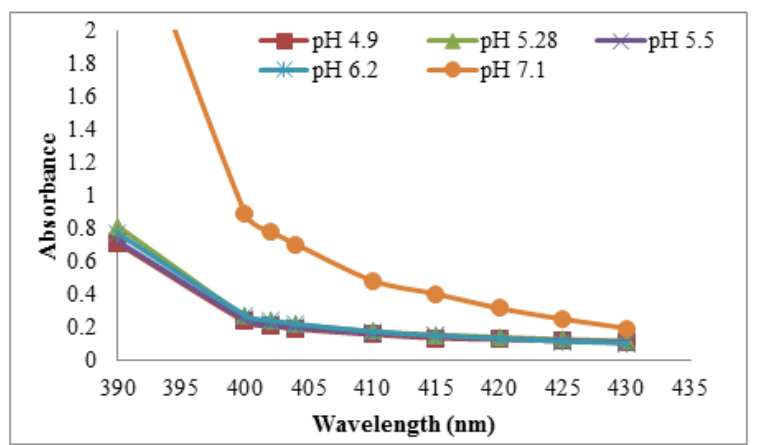

Figure 1: Absorption spectra of 4.32x10-3M azomethine-H without ascorbic acid using distilled water as blank

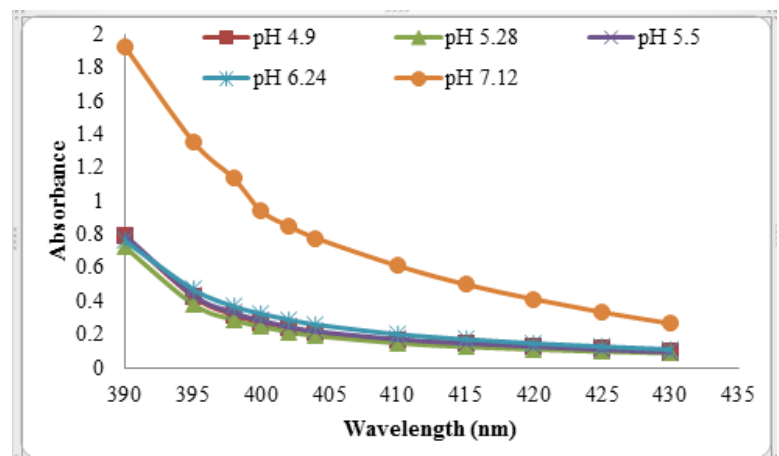

Figure 2: Absorption spectra of $4.32 \times 10-3 \mathrm{M}$ azomethine- $\mathrm{H}$ with $0.023 \mathrm{M}$ ascorbic acid using distilled water as blank

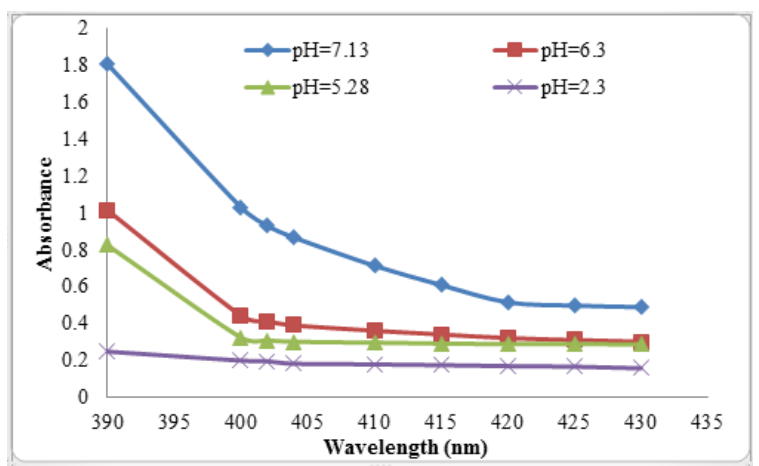

Figure 3: Absorption spectra of azomethine-boron complex using reagent blank

Generally, when azomethine-H reagent is added to sample buffered at particular $\mathrm{pH}$, it quickly form hydrolysis product within certain period of time and after which, the product re-condenses to form Schiff base with concentration equivalent to the concentration of boron in the sample. Therefore, the time for full color development is necessary to identify the waiting period needed for the sample to be stored before measurement is taken. This situation was investigated with $0.5 \mathrm{ppm}$ boron solution and reagent blank under room temperature. The scans were performed against pure distilled water. The result as shown in Figure 5 indicates that the absorbance became maximum and constant after 40minutes. Consequently, the time required for full colour development is $40 \mathrm{~min}$. All the samples treated using the recommended procedures are stored in a dark place at room temperature for 40 minutes before absorbance readings were taken. 
Boron calibration graph was constructed. Samples made from different boron standard solutions using the recommended procedure. Absorbance was measured against reagent blank after 40minutes. Plot of absorbance against boron concentration followed Beer's law from $0.1-3 \mathrm{ppmB}$ at $415 \mathrm{~nm}$. Eight point calibration as shown in Figure 6 indicates a very good linearity between absorbance and the boron standard solution with $r^{2}$ value of 0.9998 . A residuals plot was also established as shown in Figure 7 . From the chart, the residual values are randomly distributed between the positive and negative axis. This gives a further confirmation of straight fit to the data.

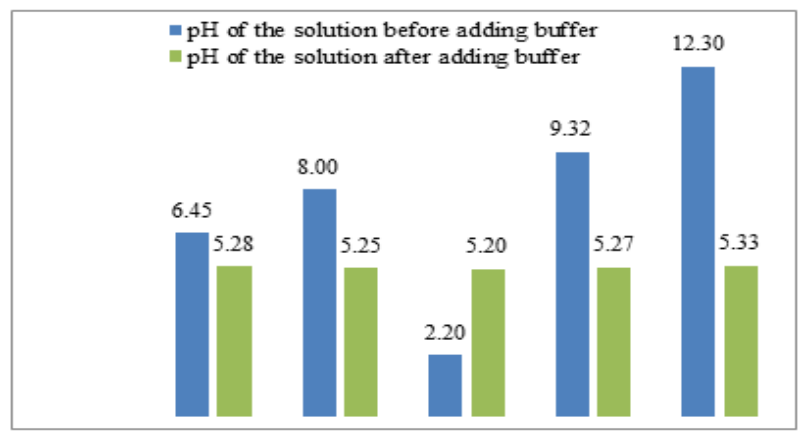

Figure 4: Effect of buffer solution on $\mathrm{pH}$ of boron solutions

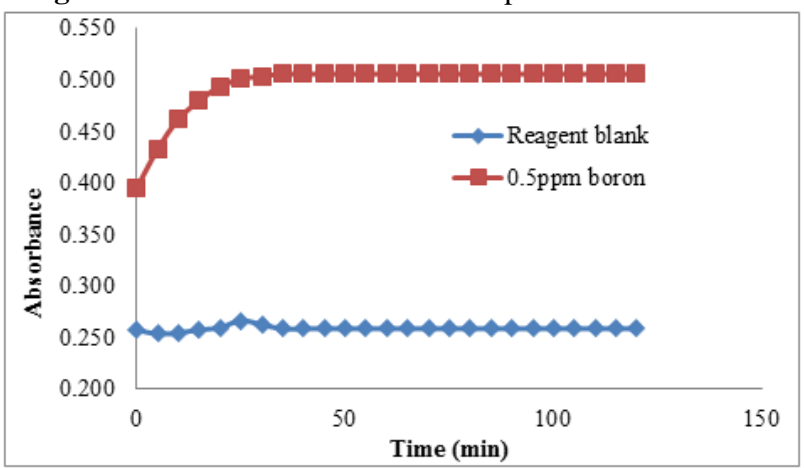

Figure 5: Kinetics of colour development for boron and reagent blank against pure distilled water

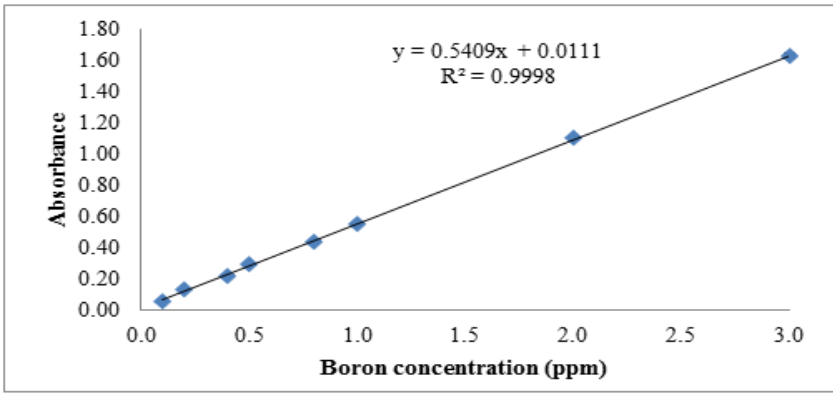

Figure 6: Boron calibration graph at $415 \mathrm{~nm}$ and $\mathrm{pH} 5.240 .02$

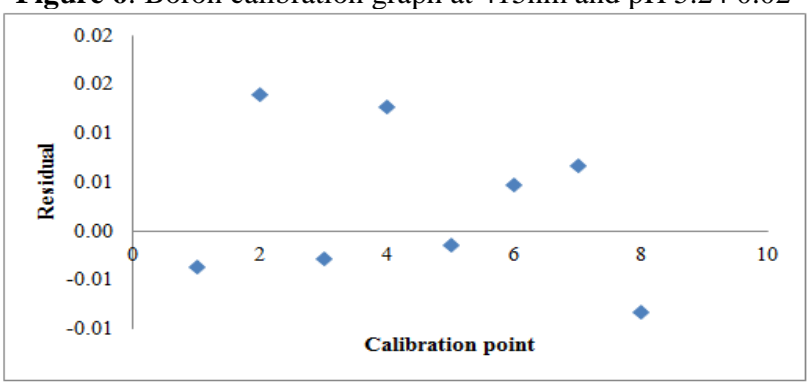

Figure 7: Chart of residuals from the regression Line for calibration points

\section{Analytical Method Validation}

The analytical method used for the determination of boron in the water was validated by computing the error or uncertainty in the measurement. The uncertainty in the regression $\left(S_{y / x}\right)$, slope $\left(S_{m}\right)$ and intercept $\left(S_{c}\right)$ were calculated using equation (1), (2) and (3) respectively.

$$
\begin{gathered}
S_{x / y}=\sqrt{\frac{\sum\left(\mathrm{y}_{\mathrm{i}}-\mathrm{y}_{\mathrm{ic}}\right)^{2}}{n-2}}------------------- \text { (1) }^{[19]} \\
S_{m}=\frac{S_{x / y}}{\sqrt{\sum\left(x_{i}-x_{a v}\right)^{2}}}---------------------(2)^{[19]}
\end{gathered}
$$




$$
S_{c}=S_{x / y} \times \sqrt{\frac{\sum x_{i}^{2}}{n \times \sum\left(x_{i}-x_{a v}\right)^{2}}}
$$

Where $y_{i}$ represent the value of measured absorbance and $y_{i c}$ is the absorbance value calculated using the regression equation obtained. $\mathrm{x}_{\mathrm{i}}$ and $\mathrm{Xav}_{\mathrm{v}}$ represent the concentration and the average concentration.

The 95\% confidence limit for slope and intercept are obtained from equation (4) and (5) each.

$$
\begin{aligned}
& m \pm t \times S_{m}-----------------------------(4) \text { [19] } \\
& c \pm t \times S_{c}------------------------------(5) \text { [19] }
\end{aligned}
$$

Limit of detection (LOD) represents the minimum value of concentration of analyte that can be measured by the instrument. This is given in terms of uncertainty of the regression and the intercept.

$$
A b s_{L O D}=c+3 \times S_{y / x}---------------------(6)[19]
$$

Table 1 below gives the estimated statistics and limit of detection at $95 \%$ confidence level

Table 1: Values of the parameters determined

\begin{tabular}{cc}
\hline Parameter & Value \\
\hline $\mathrm{n}$ & 8.00000 \\
$\mathrm{~m}$ & 0.54090 \\
$\mathrm{c}$ & 0.01110 \\
$\mathrm{X}_{\mathrm{av}}$ & 1.00000 \\
$\mathrm{Y}_{\mathrm{av}}$ & 0.55200 \\
$\mathrm{~S}_{\mathrm{y} / \mathrm{x}}$ & 0.00926 \\
$\mathrm{~S}_{\mathrm{m}}$ & 0.00345 \\
$\mathrm{~S}_{\mathrm{c}}$ & 0.00474 \\
$\mathrm{t}$ (Abs, ppm) & $0.03889,0.05137$ \\
\hline
\end{tabular}

\section{Conclusion}

Analytical method has been developed for quantification of trace amount of boron in water using azomethine- $\mathrm{H}$. The procedure was further optimized.It was found that azomethine-H reagent can be used for analysis for a period up to 20 hours from the time of its preparation. This will go a long way in reducing the cost of analysis and time. The time required for full color development was found to be $40 \mathrm{~min}$ at room temperature. Optimum $\mathrm{pH}$ of $5.24 \pm 0.02$ for the measurement at wavelength of $415 \mathrm{~nm}$ was identified. This method provides wide linearity up to $3 \mathrm{ppmB}$ with limit of detection of $0.0514 \mathrm{ppm}$ within $95 \%$ confidence level. The proposed analytical method demonstrates good sensitivity, accuracy and highly selective for determination of boron in aqueous solution.

\section{Acknowledgements}

The authors are thankful to the Federal Government of Nigeria for the funding through Education Trust Fund (ETF) of Abubakar Tafawa Balewa University Bauchi to carry out this research. The authors also acknowledge the Department of Chemical and Environmental Engineering of the University of Nottingham United Kingdom for the support provided during this study.

\section{References}

[1] Division of Agricultural Sciences and Natural Resources (DASNR) (2012) "Classification of Irrigation Water Quality" Oklahoma Cooperative Extension Fact Sheets, Oklahoma State University USA at: http://www.soiltesting.okstate.edu/Extn_Pub/F-2401web.pdf Accessed 13 Feb., 2012

[2] Lenntech B.V., (2011) Water Treatment Solutions at: http://www.lenntech.com/applications/irrigation/toxic/toxic-ions-hazard-of-irrigation-water.htm. Accessed $13^{\text {th }}$ Feb., 2012

[3] Farhat, A., Ahmad, F., and Arafat, H. (2012) Analytical techniques for boron quantification supporting desalination processes: A review. Desalination

[4] Duffy, M., Thomas, R., (1996) "Benefits of a dual-view ICP OES for the determination of boron, phosphorus, and sulfur in low alloy steels", Atomic Spectroscopy-Norwalk Connecticut, 17, 128-132.

[5] Barth, S., (1997) Comparison of NTIMS and ICP-OES methods for the determination of boron concentrations in natural fresh and saline waters, Fresenius J. Anal. Chem. 358 854-855.

[6] Tonarini, S., Leeman, W., Ferrara, G., (2001) Boron isotopic variations in lavas of the Aeolian volcanic arc, South Italy, J. Vlcanol. Geotherm. Res. 110 155-170.

[7] Aggarwal, J.K., Palmer, M.R., (1995) Boron isotope analysis. A review, Analyst 120 1301-1307

[8] Aggarwal, J.K., Sheppard, D., Mezger, K., Pernicka, E., (2003) Precise and accurate determination of boron isotope ratios by multiple collector ICP-MS: origin of boron in the Ngawha geothermal system, New Zealand, Chem. Geol. 199 331-342

[9] Sah R. N., Brown, P. H., (1997)" Boron Determination-A Review of Analytical Methods" Micro-Chemical Journal 56, 285-304

[10] Gabler, H.E., Bahr, A., (1999) Boron isotope ratio measurements with a double-focusing magnetic sector ICP mass spectrometer for tracing anthropogenic input into surface and ground water, Chem. Geol. $156323-330$.

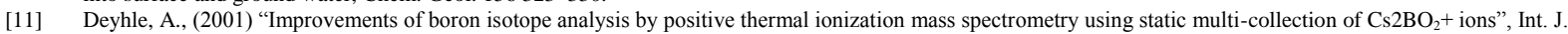
Mass spectrom. $20679-89$

[12] Rao, R.M., Parab, A.R., Bhushan, K.S., Aggarwal, S.K., (2010) High precision isotope ratio measurements on boron by thermal ionization mass spectrometry using $\mathrm{Rb} 2 \mathrm{BO} 2+$ ion, Anal. Methods 3 322-327.

[13] Zeininger, H., Heumann, K., (1983) Boron isotope ratio measurement by negative thermal ionization mass spectrometry, Int. J. Mass Spectrom. Ion Phys. 48 377380.

[14] Hemming, N., Hanson, G., (1994) "A procedure for the isotopic analysis of boron by negative thermal ionization mass spectrometry" Chem. Geol. 114 147-156.

[15] Gulens, J., and Leeson, P. K., (1980) "Direct Ion-Selective Electrode Determination of Micromolar Boron as Tetrafluoroborate" Anal. Chem. 52, 2235-2237

[16] Harp D.L., (1997)"Modifications to the azomethine-H method for determining boron in water" AnalyticaChimicaActa 346 373-379

[17] Mair Jr., J.W., Day, H.G., (1972) Curcumin method for spectrophotometric determination of boron extracted from radio frequency ashed animal tissues using 2ethyl-1, 3- hexanediol, Anal. Chem. 44 2015-2017.

[18] Ammar, S., Abdelhedi, R., Flox, C., Arias, C., Brillas, E., (2006) "Electrochemical degradation of the dye indigo carmine at boron-doped diamond anode for wastewaters remediation" Environ. Chem. Lett. 4 229-233.

[19] Stone, D. C. and Ellis, J., (2011) "Analytical chemistry: Instrumental analysis and calibration" Department of chemistry, University of Toronto at:http://www.chem.utoronto.ca/coursenotes/analsci/stats/LimDetect.html. Accessed $22^{\text {nd }}$ Aug., 2012 